\title{
Western Blot Detection of Xanthomonas Oryzae pv. Oryzae in Rice
}

\author{
Meicen Guo, Jinping Lan, Jianan Shi, Mingli Guan, Jian Wei, Lijuan Liu, Liyun Li, Shijuan Dou and Guozhen Liu*
}

College of Life Sciences, Hebei Agricultural University, Baoding 071001, China

\begin{abstract}
Bacterial blight, caused by Xanthomonas oryzae pv. oryzae (Xoo), is a severe rice disease, and rice-Xoo interactions form a model system in plant disease resistance research. To establish immuno-techniques for $X o 0$ detection, a Xoo-specific polyclonal antibody was generated using the total Xoo protein as the immunogen. A western blot procedure, which can detect as few as 3,500 Xoo cells, was established. Xoo can be detected in rice at 1-day post-inoculation (dpi) and a significant difference between the number of $X o o$ cells in resistant and susceptible reactions was found at $2 \mathrm{dpi}$. In the incompatible rice-Xoo interaction, $X_{0 o}$ can be detected within $6 \mathrm{~cm}$ of the inoculated site at $10 \mathrm{dpi}$. In the compatible interaction, Xoo can be detected within $12 \mathrm{~cm}$ of the inoculation site, while no Xoo signal was detected beyond that area in inoculated leaves and uninoculated leaves, supporting the hypothesis that rice plants harboring resistance genes have stronger inhibitory effects on Xoo propagation. This method is expected to replace the traditional manner of counting bacterial cells in laboratories and of inspecting Xoo-infected rice in paddy fields.
\end{abstract}

Keywords: Rice; Xanthomonas oryzae pv. oryzae (Xoo); Bacterial blight; Western blot; Antibody

\section{Introduction}

Rice is an important food crop, being the staple of more than half of the world's population. Bacterial blight caused by the Gram-negative bacteria Xanthomonas oryzae pv. oryzae (Xoo) is the most severe rice disease, causing significant yield losses worldwide [1]. The bacterium invades xylem tissue, either through wounds or water pores, leading to systemic infection $[2,3]$. In the past decades, a number of resistance genes from rice and avirulent genes from Xoo have been cloned. The whole genome sequencing of both rice [4] and Xoo [5] facilitated using the rice-Xoo model system to study plant-microbe interactions [6].

The detection of pathogens is critical to ensure high and stable agricultural yields. For rice bacterial blight, experienced breeders can evaluate the degree of infection based on visual inspection. In laboratories, the common detection method involves clipping the leaves, culturing the extract on bacterial medium, and then quantifying the number of Xoo based on colony-forming units [7]. A similar method for counting bacterial cells was established in Arabidopsis thaliana [8]; however, this method is time consuming, taking several days, and labor intensive.

PCR-based DNA amplification is also used in the detection of Xanthomonas pathogens $[9,10]$. Because the whole genome sequence is available, Xoo-specific primers can be designed to differentiate it from similar species [11]. In addition, gene-specific primers can also be used for PCR amplification [12]. PCR is also able to detect Xoo in rice at different time points and positions $[13,14]$.

A number of modified PCR versions, such as Padlock and LAMP, have also been used to detect Xoo in rice $[15,16]$. The amplification reactions in these methods were carried out at a constant temperature, and the products can be visualized. Such methods are expected to be used for Xoo detection in paddy fields. Plant pathogen detection using PCR is convenient and highly sensitive; however, false-positive results occur frequently [15]. Unless real-time PCR is used, regular PCR cannot detect pathogens quantitatively, thus it is difficult to monitor Xoo propagation in rice.

Immunological assays, which are also convenient, as well as specific and sensitive, were widely developed for the detection of pathogens in humans and animals [17]. The detection of pathogens in the genus of
Xanthomonas using immunological assays was first reported in the last century [18-21]. Recently, hairpin protein-specific antibodies of Xoo were generated and used to detect transgenic rice $[22,23]$. Nonetheless, an immunoassay to detect Xoo in rice has not been reported.

In recent years, fluorescent proteins have been used to monitor living organisms, such as Pseudomonas syringae, $X$. axonopodis pv. dieffenbachiae, and Xylella fastidiosa, in their hosts [24,25]. Applications of fluorescent marker systems can facilitate the detection of invading pathogens, and monitor the migration and proliferation of the bacteria. Green fluorescent protein (GFP) was introduced into Xoo to assess bacterial infections and multiplication in planta [26]. With this fluorescent marker system, the bacterial population can be measured in a day, and resistant/susceptible lines can be screened at 4 days postinoculation (dpi). Using a Xoo strain expressing GFP (Xoo-GFP), rice plants harboring XA21 can restrict the spread of Xoo from the point of infection. Moreover, the spatial distributions of Xoo populations in planta can be measured quantitatively [27]. However, the application of the fluorescent protein-based approach was limited to a specific mutant, and its virulence and pathogenicity required approval. Under certain circumstances, the auto-fluorescence from rice plants may perturb the signal intensity from the bacterial population.

In this study, a Xoo-specific polyclonal antibody was generated, and a western blot (WB) procedure was established for the quantitative detection of Xoo in rice. Xoo could be detected within $1 \mathrm{dpi}$. Moreover, incompatible and compatible interactions could be distinguished at $2 \mathrm{dpi}$. Thus, the WB operation is convenient and usually completed within 1 day. This method is expected to substitute the procedure of counting bacterial cells in laboratories and to inspect Xoo infected rice in paddy fields.

*Corresponding authors: Guozhen Liu, College of Life Sciences, Hebe Agricultural University, Baoding, 071001, China, Tel: 863127528787; Fax: 863127528250; E-mail: gzhliu@genomics.org.cn

Received August 22, 2015; Accepted August 31, 2015; Published September 03, 2015

Citation: Guo M, Lan J, Shi J, Guan M, Wei J, et al (2015) Western Blot Detection of Xanthomonas Oryzae pv. Oryzae in Rice. J Plant Pathol Microbiol S4: 005. doi:10.4172/2157-7471.S4-005

Copyright: (c) 2015 Guo M, et al. This is an open-access article distributed under the terms of the Creative Commons Attribution License, which permits unrestricted use, distribution, and reproduction in any medium, provided the original author and source are credited. 


\section{Materials and Methods}

\section{Plants and bacteria}

TP309 is a japonica rice cultivar (Oryza sativa L.), and 4021 is a homozygous transgenic line of TP309 harboring the bacterial blight resistance gene $X a 21[28,29]$. Both lines were cultivated at an experimental plot in the west campus of Hebei Agricultural University (Baoding, Hebei, China). TP309 shows a susceptible reaction (S) with Xoo race P6 (PXO99Az), while 4021 shows a resistant reaction (R) with P6 [30]. P2, P5, P6, P8, and P9 stains of Xoo and Magnaporthe oryzae stain TH12 were provided by Drs. Wen-xue Zhai and Guanghuai Jiang from the Institute of Genetics and Developmental Biology, Chinese Academy of Sciences. The DH5a stain of Escherichia coli was saved in our laboratory. Xoo was cultivated on PSA $(0.5 \%$ Bacto peptone, $2 \%$ sucrose and $0.05 \% \mathrm{~L}$-glutamic acid) plates at $28^{\circ} \mathrm{C}$ [31]. Magnaporthe oryzae was grown on medium ( $0.6 \%$ yeast extract, $0.6 \%$ peptone, $1 \%$ sucrose and $1.5 \%$ agar) at $25^{\circ} \mathrm{C}$ under a $16-\mathrm{h} / 8$-h (light/ dark) photoperiod.

\section{Rice inoculation and sample collection}

Xoo was cultured on PSA medium for 48-72 h, collected using sterilized distilled water, and then diluted to an $\mathrm{OD}_{600}$ equal to 1 . Inoculations were carried out using sterilized scissors dipped into the bacterial liquid to cut leaves. Healthy leaves from rice plants at the tillering stage were inoculated. Rice samples were collected at the time points 0 h, 1 day, 2 days, 3 days, 4 days, 5 days, 7 days, 10 days, and 15 days after inoculation. Moreover, the upper (within $6 \mathrm{~cm}$ of the inoculation site), middle (6-12 cm from the inoculation site) and lower $(12-18 \mathrm{~cm}$ away from the inoculation site) parts, as well as the uninoculated leaves of the same plant, were collected at $0 \mathrm{~h}, 3$ days, 5 days, and 10 days after inoculation. The samples were frozen in liquid nitrogen immediately after collection and then stored at $-70^{\circ} \mathrm{C}$ until use.

\section{Total protein isolation}

Rice samples were ground into a fine powder in liquid nitrogen and dissolved in extraction buffer $\left[62.5 \mathrm{mmol} \mathrm{L}^{-1}\right.$ Tris- $\mathrm{HCl}(\mathrm{pH}$ 7.4), $10 \%$ glycerol, $0.1 \%$ SDS, 2 mmol L-1 EDTA, 1 mmol L-1 PMSF, and $5 \% \beta$-mercaptoethanol]. The mixture was vortexed thoroughly and then chilled on ice for $10 \mathrm{~min}$. Cell debris was removed by centrifugation at $12,000 \times g$ for $20 \mathrm{~min}$ at $4^{\circ} \mathrm{C}$, and the supernatant was collected as a sample of rice total protein. A detailed protocol can be found in our previous report [32]. Xoo colonies growing on PSA plates were eluted using sterilized water and collected by centrifugation. The bacteria were dissolved in $4 \times$ loading buffer [50 mmol L $\mathrm{m}^{-1}$ Tris ( $\mathrm{pH}$ 6.8), $200 \mathrm{mmol} \mathrm{L}^{-1}$ DTT, 2\% SDS, $0.1 \%$ bromophenol blue, and $10 \%$ glycerol] and then heated in boiling water for $20 \mathrm{~min}$. Supernatants were collected by centrifugation as the total protein of Xoo. In addition, a fraction of the Xoo cells was sonicated for 30 cycles at $500 \mathrm{~W}$ for $10 \mathrm{~s} / 15 \mathrm{~s}$ (on/off; sonicator model: JY90-IIN, Xinzhi Biotechnique Company, Ningbo, Zhejiang, China), and then protein isolations were performed independently.

\section{Counting of bacterial cells}

The collected Xoo samples were diluted to an $\mathrm{OD}_{600}$ of 1 and then diluted further to $10^{5}, 10^{6}$, and $10^{7}$. The diluted Xoo cells at different concentrations were spread on PSA plates. Colony counting was performed and the average was used to calculate the number of Xoo bacterial cells.

\section{Production of polyclonal antibodies against $\mathrm{Xoo}$ and an ELISA test}

A polyclonal antibody against Xoo was obtained by immunizing New Zealand white rabbits (weighing $\sim 2 \mathrm{~kg}$ ) with Xoo total protein. Briefly, the rabbits were initially immunized subcutaneously at two to four different sites with Xoo total protein $(200-300 \mu \mathrm{g})$ dissolved in phosphate buffered saline (PBS, pH 7.4) and complete Freund's adjuvant in a 1:1 ratio. Then, two booster injections were performed in animals at 15-day intervals using the same amounts of antigen in incomplete Freund's adjuvant. The blood samples taken from marginal ear veins of the rabbits before immunization were used as negative controls. Bleeding $(30 \mathrm{~mL})$ was done 10 days after the last booster shot and then stored at $4^{\circ} \mathrm{C}$ overnight. Following centrifugation at $10,000 \times g$ at $4^{\circ} \mathrm{C}$ for $10 \mathrm{~min}$, the serum was obtained by decanting the supernatant. The polyclonal antibody level in the serum was determined by the ELISA method. The obtained antibody-containing serum was stored in aliquots at $-20^{\circ} \mathrm{C}$ for later use. The generation of the anti-Xoo antibody was performed by Beijing Protein Innovation Co., Ltd.

Procedures for the ELISA analysis were carried out briefly as follows: ELISA plates were coated with $100 \mu \mathrm{L}$ of antigen at a concentration of $2 \mu \mathrm{g} \mathrm{m} \mathrm{L} \mathrm{m}^{-1}$ in sodium bicarbonate buffer ( $\mathrm{pH} 9.6$ ). The coated plates were incubated at $4^{\circ} \mathrm{C}$ overnight. After blocking at $37^{\circ} \mathrm{C}$ with phosphate buffer containing $1 \%$ skimmed milk (w/v) for $2 \mathrm{~h}$, the plates were washed with phosphate buffer. Test sera were serially diluted with PBS and then added, in duplicate, to the plates and incubated for $1 \mathrm{~h}$ at $37^{\circ} \mathrm{C}$. PBS buffer was used as the blank control, and serum collected before immunization was used as the negative control. After three washing steps with the phosphate buffer, bound antibodies were detected with horseradish peroxidase-conjugated goat anti-rabbit antibodies using 3'3'5'5'-tetramethylbenidine dihydrochloride $(0.1$ $\mathrm{mg} \mathrm{m} \mathrm{L} \mathrm{m}^{-1}$ final concentration) plus $0.1 \% \mathrm{H}_{2} \mathrm{O}_{2}$ in phosphate-citrate buffer. The color development was stopped by adding $50 \mu \mathrm{L}$ per well of $2 \mathrm{~N} \mathrm{H}_{2} \mathrm{SO}_{4}$. The optical density was recorded at $450 \mathrm{~nm}$ using a spectrophotometric microplate reader.

\section{WB analysis and data collection}

A detailed WB protocol was reported previously [32]. The heat shock protein (HSP) signal was used as the loading control for rice proteins [33]. The signal intensity was extracted using the SAGE Lane 1D Gel imaging analysis software (SAGE Company, Beijing, China). The averages and standard deviations were calculated based on signals from three repeats of WB analyses, and the relative intensity of each sample was compared.

\section{Data normalization}

To normalize data collected from different WB analyses, a specific number was given to the total intensity of the WB signal, and then the relative intensity was calculated accordingly. The average and standard derivations of three repeats were used to draw a standard curve and to obtain an equation of linear regression using Excel software (Microsoft).

\section{Results}

\section{Xoo total protein isolation}

Xoo cells were collected from PSA plates and total proteins were isolated. A quantitative analysis was carried out based on a reference [34]. SDS-PAGE separated total protein was stained using Coomassie blue. To determine the effects of cell disruption on protein extraction, we compared the proteins isolated from Xoo cells with or without 
sonication. The Coomassie blue staining demonstrated that there were no significant differences between the two treatments.

\section{Evaluation of the anti-Xoo antibody}

Total proteins isolated from both Xoo-P6 cells with or without sonication were used as the immunogens to inject New Zealand white rabbits to generate polyclonal anti-Xoo antibodies. ELISA experiments were performed to evaluate the antibody titers using 96-well plates coated by immunogen (Figure 1). As Figure 1 shows, even at a 102,400 $\times$ dilution, the antibodies could still detect signals significantly higher than in the blank controls, and the titers of two antibodies were similar. However, the titer of the anti-Xoo antibody generated using protein isolated from sonicated Xoo cell (Ab-s) was higher than that generated from the non-sonicated sample, therefore, the Ab-s antibody was used in the experiments. To detect the specificity of the antibody, total proteins isolated from rice (TP309), E. coli (DH5a), Xoo (P2, P6, P8, $\mathrm{P} 9$, and $\mathrm{P} 10$ ), and M. oryzae (TH12) were separated on SDS-PAGE and assayed using a WB (Figure 2). The antibody could detect different races of Xoo and did not cross-react with rice, E. coli, or M. oryzae, indicating that the antibody is highly specific to the Xoo protein. In addition, several major bands were detected using a WB of the Xoo protein, supporting the hypothesis that multiple antigenic epitopes existed to produce the polyclonal antibodies.

\section{Sensitivity and standard curve of the WB detection of Xoo}

To test the sensitivity of the WB detection of Xoo, serially diluted samples containing different Xoo cell numbers were assayed using WB. The minimum number of $X o o$ cells detectable by WB was 3,500 (in 20 $\mu \mathrm{L}$ loading buffer, $\sim 1.75 \times 10^{5}$ colony-forming units $\left.\mathrm{m} \mathrm{L}^{-1}\right)$. Within a certain range, there was a linear relationship between the signal intensity of WB and the number of Xoo cells (data not shown). We next detected the Xoo protein when mixed with rice samples (TP309) (Figure 3). The rice proteins did not interfere with Xoo protein detection, and there was a linear relationship, within a certain range, between the WB signal intensity and the Xoo cell number. The linear regression equation was: $y=1.6422 \times-3.0408$, with a correlation coefficient $\left(R^{2}\right)$ of 0.9643 . This result provided the groundwork for the detection of Xoo in planta.

\section{Quantitative measurements of Xoo in planta}

To detect Xoo in rice plants, Xoo race P6 was used to inoculate TP309 and 4021 using the leaf-clipping method. At $15 \mathrm{dpi}$, the lesion length caused by the TP309-P6 interaction was $\sim 14 \mathrm{~cm}$, indicating a typical susceptible reaction, and the lesion length caused by the 4021 P6 interaction was $\sim 1 \mathrm{~cm}$, indicating a typical resistant reaction (Figure 4). Leaf samples were collected at 0 h, 1 day, 2 days, 3 days, 4 days, 5 days, 7 days, 10 days, and 15 days at the inoculation site $(\sim 1 \mathrm{~cm}$ in length). Total protein was isolated and separated using SDS-PAGE. Then, a WB analysis was performed. The Xoo signal in both interactions increased proportionately with the extended inoculation time. To obtain insightful results, total proteins isolated from TP309-P6 and 4021-P6 interactions at 1, 2, 3, 4, and 5 dpi were analyzed using WB in parallel. The abundance of HSP protein in rice was used as a loading control. As shown in Figure 5, the Xoo signal could be detected in rice at $1 \mathrm{dpi}$, and significant differences in the number of Xoo cells in the resistant/susceptible reactions were found at $2 \mathrm{dpi}$. With an extended inoculation time, the difference between the two interactions became more obvious.

\section{The distribution of Xoo in rice plants}

Leaf samples, including the upper $(1-6 \mathrm{~cm})$, middle $(6-12 \mathrm{~cm})$, and lower $(12-18 \mathrm{~cm})$ parts of inoculated leaves and uninoculated leaves of
4021 and TP309, at 0 h, 3 days, 5 days, and 10 days after inoculation were collected, and total protein was isolated and assayed by WB using the anti-Xoo antibody. At 3 and $5 \mathrm{dpi}$ for both samples, Xoo could be detected only at the inoculation site (data not shown). At $10 \mathrm{dpi}$, in the incompatible interaction (4021-P6), Xoo was detected only in the upper part of inoculated leaves (Figure 6). However, in the compatible interaction (TP309-P6), the Xoo signal was detected in the upper and middle parts of inoculated leaves. Xoo was not detectable in the lower parts of inoculated leaves or uninoculated leaves of both compatible and incompatible interactions. Based on the results, we concluded that, within 10 days of clipping inoculation, rice plants with or without resistance genes limited the multiplication of Xoo within 6 or $12 \mathrm{~cm}$ of the inoculation site, respectively. The quantitative difference leads to a qualitative difference.

\section{Discussion}

In this study, an immunological method was established that could detect Xoo conveniently in planta. This method provides an alternative approach to determine the quantity, propagation rate, and distribution of Xoo in rice, and it is expected to replace the traditional leaf-clipping method, at least in some instances.

The sensitivity of the established WB procedure is quite high, detecting as few as 3,500 Xoo cells, which is sensitive enough to detect Xoo cells at $1 \mathrm{dpi}$. Moreover, the antibody is highly specific to Xoo, and it is conserved among different races of Xoo. It did not cross-react with protein samples isolated from rice, E. coli, and M. oryzae. The $\mathrm{WB}$ procedure is well established in molecular biology laboratories and, in general, the vitality of Xoo has little influence on WB detection. Using the established procedure, resistant or susceptible interactions can be distinguished by $2 \mathrm{dpi}$, much earlier than with phenotypic observations, which usually take 5-6 days to express symptoms.

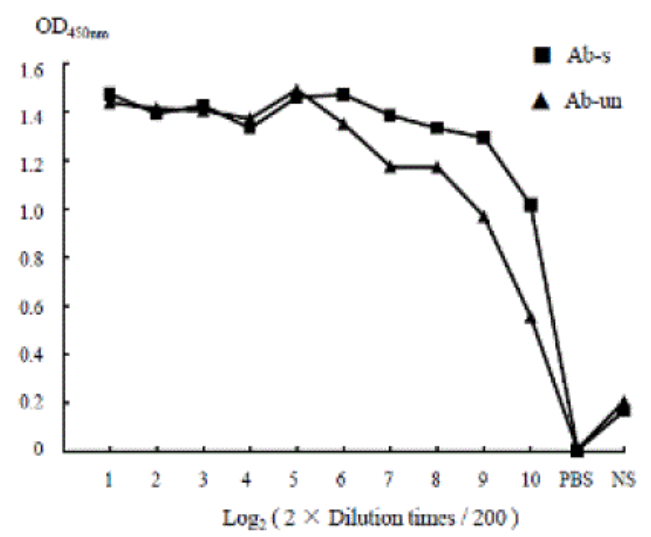

Figure 1: Titer evaluation of anti-Xoo antibodies using ELISA. ELISA plates were coated overnight with $0.2 \mu \mathrm{g}$ of $X_{0 o}$ protein at $4^{\circ} \mathrm{C}$. After blocking at $37^{\circ} \mathrm{C}$ with phosphate buffer containing $1 \%$ skimmed milk $(\mathrm{W} /)$ for $2 \mathrm{~h}$, plates were washed with phosphate buffer. Test sera were serially diluted with PBS, then added in duplicate to the plates and incubated for $1 \mathrm{~h}$ at $37^{\circ} \mathrm{C}$. PBS buffer was used as the blank control and serum collected before immunization was used as the negative control (NS). After washing three times with the phosphate buffer, bound antibodies were detected with horseradish peroxidase-conjugated goat anti-rabbit antibodies, and revealed using 3'3'5'5'-tetramethylbenidine dihydrochloride and $\mathrm{H}_{2} \mathrm{O}_{2}$ in phosphatecitrate buffer. The color development was stopped by adding $\mathrm{H}_{2} \mathrm{SO}_{4}$. The optical density was recorded at $450 \mathrm{~nm}$ using a spectrophotometric microplate reader.

$\mathrm{Ab}-\mathrm{s}$ ) Anti-Xoo antibody generated using protein isolated from sonicated $\mathrm{XoO}_{\mathrm{O}}$ cells as the immunogen. Ab-un: Anti-Xoo antibody generated using protein isolated from intact (un-sonicated) Xoo cells as the immunogen. PBS: PBS buffer; NS: negative sera. 


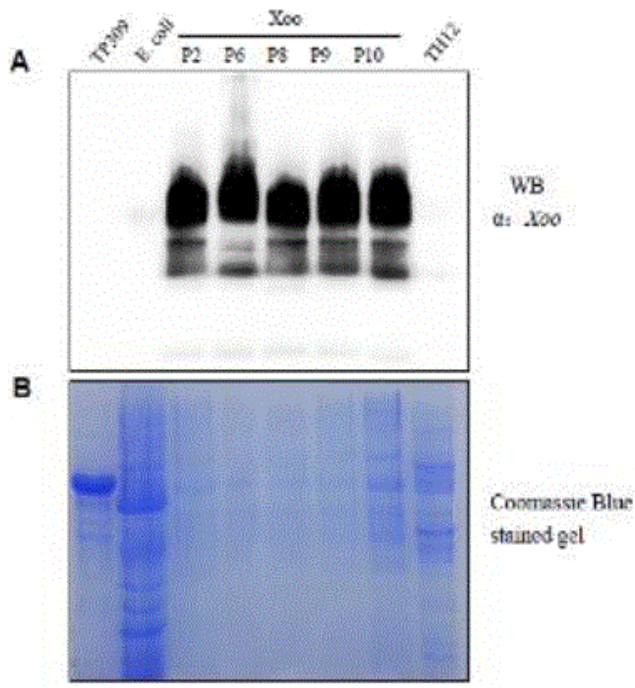

Figure 2: Anti-Xoo antibody specificity evaluation using a WB analysis. Total proteins were isolated from uninfected rice (TP309), E. coli (DH5a), Xoo (P2, P6, P8, P9, and P10), and M. oryzae (TH12). SDS-PAGE separated proteins were transferred to PVDF membranes, assayed using (A) the anti$X o o$ antibody, and (B) a parallel gel was stained with Coomassie blue.
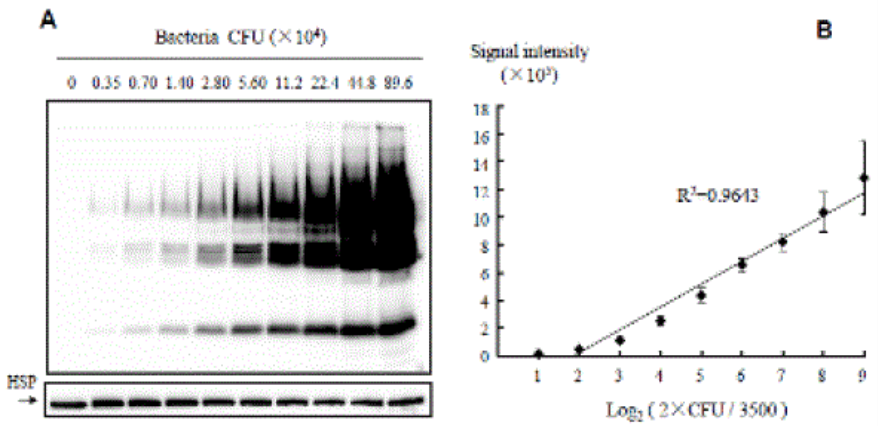

Figure 3: Detection of the Xoo protein when mixed with rice samples using a WB analysis.

A) Total Xoo proteins were mixed with samples isolated from rice TP309 and separated by SDS-PAGE. A WB analysis was performed using the anti-Xoo antibody. HSP: The abundance of HSP protein in rice was determined and used as a loading control.

B) Quantification of signal intensity collected from three repeats of WB analysis. The average and standard derivations were calculated. The standard curve was generated and a linear regression was performed.

Additionally, compared with DNA- and RNA-based technologies, the false-positive rate is much lower using WB detection. It can also be standardized for high throughput using an automatic WB analyzer and standard reference Xoo samples.

Xoo infects rice leaves through hydathodes or wound sites and then enters the xylem vessels where it can multiply and spread. Smear inoculations were used to infect rice leaves and track the multiplication of GFP-tagged Xoo. It was found that the fluorescence intensity in the resistant rice leaves was significantly weaker than that in susceptible rice leaves at $9 \mathrm{dpi}$ [27]. However, smear inoculation infected the whole rice leaf simultaneously, making it impossible to monitor the speed of Xoo spread in planta. Using PCR technology, Xoo was found within $6 \mathrm{~cm}$ of the inoculation site 2-3 days after clipping inoculation in susceptible rice-Xoo combinations [13, 14].

In this study, the spread of Xoo by clipping inoculation was investigated using immunological methods. The results showed that at $10 \mathrm{dpi}$, the distance $X o o$ spread was limited to $6 \mathrm{~cm}$ of the inoculation site on leaves in incompatible rice-Xoo interactions, while in compatible interactions, the distance of Xoo spread was 12 $\mathrm{cm}$ from the inoculation site. The number of Xoo cells and the spread distance in resistant and susceptible combinations differed from each other. Currently, the detection of Xoo in planta can be achieved using either PCR or immunological methods; however, the determination of resistance or susceptibility still requires a more sophisticated analysis. Rice can tolerate certain amounts of Xoo, therefore, the difference between resistance and susceptibility is related to several factors, such as the presence or absence of certain Xoo races, the quantity of Xoo cells, and the presence or absence of rice resistance genes.

The establishment of this immunological method provides an effective way to investigate the plant-microbe rice-Xoo model system. It will be helpful in studying plant disease resistance mechanisms, and it may be used in the management of rice production. Moreover, the

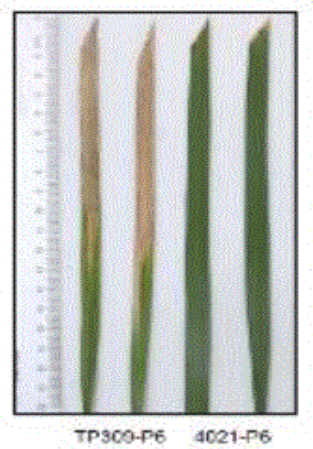

B

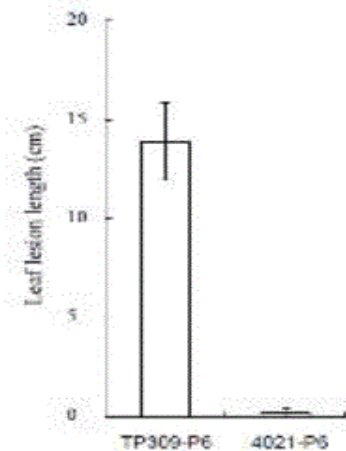

Figure 4: A phenotypic analysis of rice leaves inoculated with Xoo A. Picture of rice leaves taken at 15 days after $X o o$ inoculation.

B. Average of lesion lengths on rice leaves. At least five inoculated leaves were measured, and averages and standard derivations were calculated. TP309-P6: TP309 plants inoculated with Xoo P6 showing a compatible interaction; 4021-P6: 4021 plants inoculated with Xoo P6 showing an incompatible interaction.

A
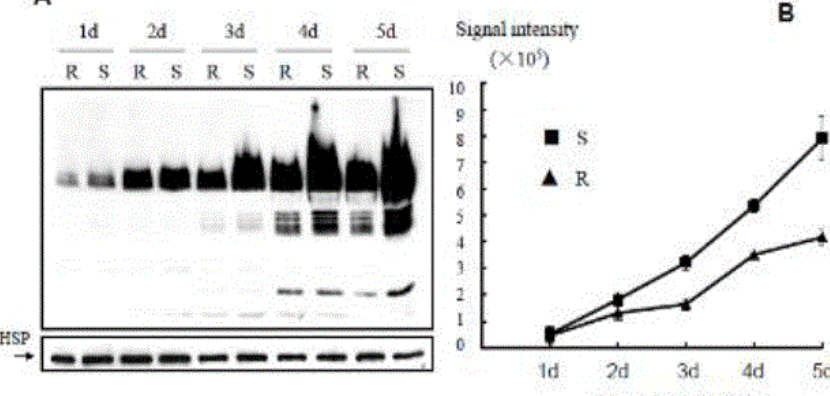

Davs after inoculation

Figure 5: Comparison of Xoo levels in rice leaves between compatible and incompatible interactions

A) WB detection of $X o o$ levels in rice leaves at different time points after inoculation. At $1,2,3,4$, and 5 days after $X_{0 o}$ inoculation total proteins were isolated from rice leaves. SDS-PAGE separated total proteins were transferred to PVDF membrane and incubated with an anti-Xoo antibody. HSP: The abundance of HSP protein in rice was used as a loading control.

B) Quantification of Xoo levels detected using WB. The signal intensities were collected from three independent WBs and normalized based on the total signal intensities within a gel. The averages and standard derivations were calculated. R: Samples collected from Xoo-inoculated 4021 rice plants; S: Samples collected from Xoo-inoculated TP309 rice plants. 


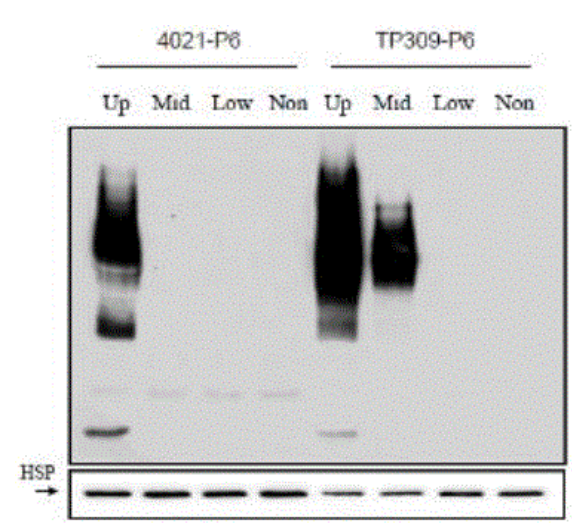

Figure 6: The distribution of $X_{0 o}$ in rice leaves. Samples were collected from rice leaves at $10 \mathrm{dpi}$ with $\mathrm{Xoo}_{\mathrm{O}}$, total proteins were isolated and assayed using WB with the anti-Xoo antibody. 4021-P6: Samples collected from Xooinoculated 4021 plants; TP309-P6: Samples collected from Xoo-inoculated TP309 rice plants. Up, Mid, and Low: The upper (1-6 cm), middle $(6-12$ $\mathrm{cm})$, and lower $(12-18 \mathrm{~cm})$ parts of inoculated leaves, respectively; Non: Inoculated leaves from the same rice plants. HSP: The abundance of HSP protein in rice was used as a loading control.

availability of a highly specific antibody will be useful in investigating the subcellular localization of Xoo via immunohistochemistry and to the development of a testing strip or ELISA kit, which could be used during rapid quarantine seed inspections and even in the surveillance for rice plants in the paddy fields.

\section{Acknowledgments}

This work was supported by the National Natural Science Foundation of China (No. 31171528)

\section{Conflict of Interest}

There is no conflict of interest between authors for this manuscript.

\section{References}

1. Cheatham MR, Rouse MN, Esker PD, Ignacio S, Pradel W, et al. (2009) Beyond yield: plant disease in the context of ecosystem services. Phytopathology 99 : 1228-1236.

2. Shekhawat GS, Srivastava DN (1972) Mode of Infection in Bacterial Lea Streak of Rice and Histology of the Diseased Leaf1). Journal of Phytopathology 74: 84-90.

3. White FF, Yang B (2009) Host and pathogen factors controlling the riceXanthomonas oryzae interaction. Plant Physiol 150: 1677-1686.

4. Sasaki T, Matsumoto T, Yamamoto K, Sakata K, Baba T, et al. (2002) The genome sequence and structure of rice chromosome 1. Nature 420: 312-316.

5. Lee BM, Park YJ, Park DS, Kang HW, Kim JG, et al. (2005) The genome sequence of Xanthomonas oryzae pathovar oryzae KACC10331, the bacterial blight pathogen of rice. Nucleic Acids Res 33: 577-586.

6. Shen Y, Ronald P (2002) Molecular determinants of disease and resistance in interactions of Xanthomonas oryzae pv. oryzae and rice. Microbes Infect 4: 1361-1367.

7. Xu WH, Wang YS, Liu GZ, Chen X, Tinjuangjun $P$, et al. (2006) The autophosphorylated Ser686, Thr688, and Ser689 residues in the intracellular juxtamembrane domain of XA21 are implicated in stability control of rice receptor-like kinase. Plant J 45: 740-751.

8. Tornero $P$, Dangl JL (2001) A high-throughput method for quantifying growth of phytopathogenic bacteria in Arabidopsis thaliana. Plant J 28: 475-481.

9. Leite RP, Jones J, Somodi GC, Minsavage GV (1995) Detection of Xanthomonas campestris pv.vesicatoria associated with pepper and tomato seed by DNA amplification. Plant J 79: 917-922.

10. Mavrodieva V, Levy L, Gabriel DW (2004) Improved sampling methods for realtime polymerase chain reaction diagnosis of citrus canker from field samples. Phytopathology 94: 61-68.
11. Chen Y, Zuo R1, Zhu Q1, Sun Y1, Li M1, et al. (2014) MoLys2 is necessary for growth, conidiogenesis, lysine biosynthesis, and pathogenicity in Magnaporthe oryzae. Fungal Genet Biol 67: 51-57.

12. Urayama S, Fukuhara T, Moriyama H, Toh EA, et al. (2014) Heterologous expression of a gene of Magnaporthe oryzae chrysovirus 1 strain A disrupts growth of the human pathogenic fungus Cryptococcus neoformans. Microbiology and immunology 58: 294-302.

13. Song ES, Lee BM, Lee CS, Park YJ (2012) PCR-based Rapid Assay for Discriminative Detection of Latent Infections of Rice Bacterial Blight. Journal of Phytopathology 160: 195-200.

14. Song ES, Kim SY, Noh TH, Cho H, Chae SC, et al. (2014) PCR-based assay for rapid and specific detection of the new Xanthomonas oryzae pv. oryzae $\mathrm{K} 3 \mathrm{a}$ race using an AFLP-derived marker. J Microbiol Biotechnol 24: 732-739.

15. Lang JM, Langlois P, Nguyen MH, Triplett LR, Purdie L, et al. (2014) Sensitive detection of Xanthomonas oryzae Pathovars oryzae and oryzicola by loopmediated isothermal amplification. Appl Environ Microbiol 80: 4519-4530.

16. Tian Y, Zhao Y, Xu R, Liu F, Hu B, et al. (2014) Simultaneous Detection of Xanthomonas oryzae pv. oryzae and $\mathrm{X}$. oryzae pv. oryzicola in Rice Seed Using a Padlock Probe-Based Assay. Phytopathology 104: 1130-1137.

17. Ermolli M, Prospero A, Balla B, Querci M, Mazzeo A, et al. (2006) Development of an innovative immunoassay for CP4EPSPS and Cry1AB genetically modified protein detection and quantification. Food Addit Contam 23: 876-882.

18. Lazarovits G, Zutra D, Bar-Joseph M (1987) Enzyme-linked immunosorbent assay on nitrocellulose membranes (dot-ELISA) in the serodiagnosis of plant pathogenic bacteria. Can J Microbiol 33: 98-103.

19. Huang B, Zhu H, Hu G, Li Q, Gao J, et al. (1992) The production of hybridoma cell line secreting monoclonal antibodies against Xanthomonas campestris pv. oryzae and its application in the classification of strains. Chin J Biotechnol 8 : 139-144.

20. Jones JB, Somodi GC, Scott JW (1997) Increased ELISA sensitivity using a modified extraction buffer for detection of Xanthomonas campestris pv. vesicatoria in leaf tissue. J Appl Microbiol 83: 397-401.

21. Vijayanand GK, Krishnappa M, Shetty HS (1999) An approach to obtain specific polyclonal antisera to Xanthomonas campestris pv. cyamopsidis and its potential application in indexing of infected seeds of guar. J Appl Microbiol 87: 711-717.

22. Li M, Shao M, Lu XZ, Wang JS (2005) Biological activities of purified harpin(Xoo) and harpin $\left(X_{O O}\right)$ detection in transgenic plants using its polyclonal antibody. Acta Biochim Biophys Sin (Shanghai) 37: 713-718.

23. Shao M, Li M, Pan XM, Wang JS (2006) Preparation, Characterization, and Application of Antiharpinxoo Antibody. Agricultural Sciences in China 5: 512 516

24. Chen Y, Zhai S, Sun Y, et al. (2015) MoTup1 is required for growth conidiogenesis and pathogenicity of Magnaporthe oryzae. Mol Plant Pathol .

25. Li Y, Ye Z, Nie Y, Zhang J, et al. (2015) Comparative phosphoproteome analysis of Magnaporthe oryzae-responsive proteins in susceptible and resistant rice cultivars. Journal of proteomics 115: 66-80.

26. Han SW, Park CJ, Lee SW, Ronald PC (2008) An efficient method for visualization and growth of fluorescent Xanthomonas oryzae pv. oryzae in planta. BMC Microbiol 8: 164

27. Nozue K, Park CJ, Ronald P (2011) Quantitative Measurements of Xanthomonas Oryzae pv. Oryzae Distribution in Rice Using Fluorescent-Labeling. J Plant Bio 54: $269-274$

28. Chadha S, Sharma M2 (2014) Transposable elements as stress adaptive capacitors induce genomic instability in fungal pathogen Magnaporthe oryzae. PLoS One 9: e94415.

29. Song WY, Wang GL, Chen LL, Kim HS, Pi LY, et al. (1995) A receptor kinaselike protein encoded by the rice disease resistance gene, Xa21. Science 270 1804-1806.

30. Lee SW, Han SW, Sririyanum M, Park CJ, et al. (2009) A type I-secreted sulfated peptide triggers XA21-mediated innate immunity. Science 326: 850853.

31. Wang Y, Kwon SJ2, Wu J1, Choi J3, Lee YH3, et al. (2014) Transcriptome Analysis of Early Responsive Genes in Rice during Magnaporthe oryzae Infection. Plant Pathol J 30: 343-354. 
Citation: Guo M, Lan J, Shi J, Guan M, Wei J, et al (2015) Western Blot Detection of Xanthomonas Oryzae pv. Oryzae in Rice. J Plant Pathol Microbiol S4: 005. doi:10.4172/2157-7471.S4-005

Page 6 of 6

32. Bai H, Lan JP, Gan Q, Wang XY, Hou MM, et al. (2012) Identification and expression analysis of components involved in rice Xa21-mediated disease resistance signalling. Plant Biol (Stuttg) 14: 914-922.

33. Li X1, Bai H, Wang X, Li L, Cao Y, et al. (2011) Identification and validation of rice reference proteins for western blotting. J Exp Bot 62: 4763-4772.
34. Bradford MM (1976) A rapid and sensitive method for the quantitation of microgram quantities of protein utilizing the principle of protein-dye binding. Anal Biochem 72: 248-254.

This article was originally published in a special issue, Host-parasite Interaction handled by Editor(s). Dr. Naotaka Furuichi, Niigata University 